\title{
Hepatoprotective Effect of Azadirachta indica Leaf Fractionated Extracts against Snake Venom Toxicity on Albino Rats
}

\author{
Ibrahim Sani $^{1 *}$, Rabi'u Aliyu Umar ${ }^{2}$, Sanusi Wara Hassan ${ }^{2}$, Umar Zaki Faruq ${ }^{3}$, Fatima Bello ${ }^{1}$, Habiba Aminu ${ }^{1}$ and Amina \\ Sulaiman ${ }^{1}$ \\ ${ }^{1}$ Department of Biochemistry, Faculty of Life Sciences, Kebbi State University of Science and Technology, Aliero, Nigeria \\ ${ }^{2}$ Department of Biochemistry, Faculty of Science, Usmanu Danfodiyo University, Sokoto, Nigeria \\ ${ }^{3}$ Department of Pure and Applied Chemistry, Faculty of Science, Usmanu Danfodiyo University, Sokoto, Nigeria
}

DOI: $10.36348 /$ sjbr.2020.v05i06.004

| Received: 13.05.2020 | Accepted: 10.06.2020 | Published: 14.06.2020

*Corresponding author: Ibrahim Sani

Abstract

Snakebite envenomation occurs due to subcutaneous or intramuscular injection of venom into a victim resulting in complicated pharmacological effects that depend on the combined and synergistic action of toxic and non-toxic components. Hence, this research was aimed at evaluating the hepato-protective effect of Azadirachta indica leaf fractionated extracts against snake venom toxicity in albino rats. A. indica leaf was collected, authenticated and extracted using $95 \%$ methanol followed by fractionation using hexane and ethylacetate. Albino rats of both sexes were randomly divided into five (5) groups of six (6) rats each (3 males and 3 females). Group 1 received $1 \%$ aqueous solution of Tween- 80 orally. Groups 2, 3 and 4 received $0.2 \mathrm{mg} / \mathrm{kg} \mathrm{b.w.} \mathrm{of} \mathrm{the} \mathrm{venom,} \mathrm{but} 3$ and 4 were treated with $100 \mathrm{mg} / \mathrm{kg}$ b.w. of hexane fraction and ethylacetate fraction respectively. Group 5 received $0.2 \mathrm{mg} / \mathrm{kg}$ b.w. of the venom and treated with standard conventional antivenin. The hexane and the ethylacetate fractions significantly provided protection on the liver probably via inactivation of the venom cytotoxins leading to the hepatic protection. Among the two (2) fractions administered to the envenomed rats, only hexane fraction was able to significantly $(\mathrm{P}<0.05)$ reduce the activity of serum LDH compared to the venom control group. None of the fractions or the standard antivenin reduced the serum AST, but the levels of total and direct bilirubin were significantly $(\mathrm{P}<0.05)$ lowered in the envenomed rat compared to the venom control group. In contrast, the standard antivenin significantly increased the serum TP. This research has provided a scientific proof on the antivenom properties of $A$. indica leaf, and the plant extracts tested can be used for the detoxification of the snake venom toxicity.

Keywords: Snakebite, Venom, Envenomation, Azadirachta indica, Hepatoprotection.

Copyright @ 2020: This is an open-access article distributed under the terms of the Creative Commons Attribution license which permits unrestricted use, distribution, and reproduction in any medium for non-commercial use (NonCommercial, or CC-BY-NC) provided the original author and source are credited.

\section{INTRODUCTION}

Snake venoms are highly modified saliva containing zootoxins used by the snakes to immobilize and digest prey or to serve as a defense mechanism against a potential predator or other threats [1]. The venom produced by the snakes' venom gland apparatus is delivered by an injection system of modified fangs that enable the venom to penetrate into the target [2].

Different toxins from snake venom exhibit different modes of action [2]. Some distinct types of venom toxins that act differently [1] include: Proteolytic toxins (found in cobras and mambas venom) distort the molecular structure of the affected body muscles or organs causing necrosis and disability [3]; Cardiotoxic toxins (found in the venom of Naja species) specifically affect the heart by impairing muscle contraction causing the heart to beat irregularly or completely stop beating; Neurotoxic toxins (found in the venom of cobras, mambas, sea snakes, kraits and coral snakes) act on the nervous system and brain resulting in tetany where the nerve stays stimulated, causing incontrollable muscle contractions that can lead to death; Dendrotoxic toxins (found in cobras and mambas venom) inhibit neurotransmissions by blocking the exchange of positive and negative ions across the neuronal membrane leading to no nerve impulse, thereby paralyzing the victim; Haemotoxic venoms (found in the venom of Viperidae family members) cause haemorrhagic activity and the induction of local and systemic bleeding. They also possess diverse functions such as disruption of haemostasis mediated by pro-coagulant or anticoagulant effects, platelet aggregation, and apoptotic or pro-inflammatory activities [4]. These differences in composition of 
venom depend upon the species, geographical location, habitat, climate, age, etc [5].

Azadirachta indica (Neem tree) belongs to the Meliaceae (mahogany) family. It is known as 'Dogon yaro or Darbejiya' in Hausa Language. The neem tree has long been recognized for its unique properties in improving human health [6]. It is grown in most tropical and sub-tropical areas of the world for shade, reforestation and for the production of raw material for natural insecticides and medicines [7]. Different parts of $A$. indica tree such as seeds, leaves, flowers, and the bark are widely used for different purposes [8]. Its extracts have been extensively used in health management since ancient times and have a variety of health-promoting properties including antisnake venom efficacy $[9,10]$.

It has been demonstrated by earlier studies that crude extract of neem leaves possesses significant hepatoprotective activities [11, 12]. Hepatoprotective role of neem-derived azadirachtin- $\mathrm{A}$ and its other ingredients has been reported. In a study by Baligar et al., [13], carbon tetrachloride $\left(\mathrm{CCl}_{4}\right)$ was used to induce hepatotoxicity in animal models and it was observed that the disease control groups exhibited decreased total protein level and significantly increased aspartate aminotransferase (AST), alanine aminotransferase (ALT) and alkaline phosphatase levels. Treatment with azadirachtin-A significantly improved the reference range of these proteins and enzymes. In addition, the histological and ultra-structural studies confirmed that pretreatment with azadirachtin-A reduced hepatocellular necrosis.

In another study, hepatoprotective effect of the leaf extract was examined using albino rats. Aqueous leaf extract significantly reduced elevated levels of AST and ALT. Additionally, liver necrosis was also found to be reduced as observed macroscopically and histologically [14]. Another finding concluded that aqueous leaf extract of neem prevents and reverses hepatotoxic damage caused by anti-tubercular drugs [15].

Based on the reports by earlier studies that extracts of neem leaf possess significant hepatoprotective activities, this research was aimed at evaluating the hepato-protective effect of $A$. indica leaf fractionated extracts against snake venom toxicity in albino rats.

\section{MATERIALS AND METHODS Study Area}

The research was conducted between April, 2018 to July, 2018 in Biochemistry Research Labouratory, Department of Biochemistry, Faculty of Life Sciences, Kebbi State University of Science and Technology, Aliero, Nigeria.

\section{Experimental Animals}

Adult Wister albino rats of both sexes aged 3 4 months and weighing between $150-200 \mathrm{~g}$ were used for the experiments. They were purchased from National Veterinary Research Institute, Vom, Nigeria and kept under standard laboratory conditions (22$24^{\circ} \mathrm{C} ; 12: 12 \mathrm{~h}$ dark/light cycle). The animals were allowed free access to both food (commercial rodents pellets) and water ad libitum [16], they were allowed to acclimatize for 2 weeks. Weight of each rat was taken before the commencement of the experiment. All animal experiments were conducted in accordance with the guidelines for the use and care of experimental animals [17].

\section{Standard Snake Venom Antiserum (Antivenin)}

The lyophilized polyvalent snake venom antiserum (Batch No.: 01AS83659, Man. Date: March, 2018, Exp. Date: February, 2021) was used as standard to compare with the efficacy of the plant extract. It was produced by a standard pharmaceutical company (VINS Bioproducts Limited, Andhra Pradesh, India).

\section{Naja nigricollis}

The snake specie (Naja nigricollis) used was captured and housed in a wooden cage with the help of a snake-charmer. After collection, it was duly identified by a zoologist at the Department of Animal and Environmental Biology, Kebbi State University of Science and Technology, Aliero, Nigeria. Its venom was milked and used for the experiments.

\section{Milking of Venom}

The venom was collected between $5.00 \mathrm{pm}$ to $6.00 \mathrm{pm}$, in a low light condition at ambient temperature according to the method of Goswami et al., [18] by using a short-acting general anesthesia; halothane (Piramal Healthcare Limited, U.K.). The glands below the eyes of the snake were compressed to release the stored venom into a cleaned and sterilized container.

\section{Preparation of Venom}

After milking, the venom was lyophilized using a freeze-dryer (Millrock Technology, USA) and kept inside a refrigerator (HR135A, Haier-Thermocool, Lagos, Nigeria) in a light resistant and air-tight container. Before use, the lyophilized venom was reconstituted in $0.9 \%$ saline (regarded as the venom) and kept at $4{ }^{\circ} \mathrm{C}$. The venom concentration was expressed in terms of dry weight ( $\mathrm{mg} / \mathrm{ml})$ [19].

\section{Collection and Authentication of the Plant Material}

Azadirachta indica leaf was collected within Aliero town, Kebbi State, Nigeria. It was authenticated at the herbarium of the Department of Plant Science and Biotechnology, Kebbi State University of Science and 
Technology, Aliero, and voucher specimen was deposited there; VN:083.

\section{Preparation of Crude A. indica Leaf Methanol Extract}

The extract was prepared according to the method of Dupont et al., [20]. The collected leaf was cleaned with water and air-dried under shade, pulverized using pestle and mortar. One kilogramme (1 $\mathrm{kg}$ ) of the powdered leaf was measured and soaked in $2.5 \mathrm{~L}$ of $95 \%$ methanol. The mixture was then kept at room temperature for $24 \mathrm{~h}$ and filtered twice; initially with a muslin cloth and later with a Whatman filter paper No.1. The filtrate was evaporated to dryness at $45^{\circ} \mathrm{C}$ using rotary evaporator. The residue was further fractionated.

\section{Solvent-Fractionation of Crude $A$. indica Leaf Methanol Extract}

The crude methanol extract of the A. indica leaf was fractionated by liquid-liquid extraction using n-hexane and ethylacetate in increasing order of polarity. Two hundred grammes $(200 \mathrm{~g})$ of the dried methanol extract were reconstituted in $400 \mathrm{ml}$ of distilled water in a 1 liter separating funnel. This was then partitioned sequentially with equal volume of $n-$ hexane, and ethylacetate to yield the n-hexane and ethylacetate fractions. The fractions were concentrated to dryness and the residues were kept in a refrigerator in an air-tight container for further use. Before use, each fraction was reconstituted in $1 \%$ aqueous solution of Tween-80 (polysorbate) and was expressed in terms of dry weight $(\mathrm{mg} / \mathrm{ml})$.

\section{Evaluation of the Hepatoprotective Effect}

To evaluate the protective effect of the hexane and the ethylacetate fractions, biochemical parameters of hepatic functions were analyzed.

Thirty (30) rats were used. They were distributed randomly into five (5) groups of six (6) rats each (3 males and 3 females) and were treated as follows:

Group 1: received $1 \%$ aqueous solution of Tween-80 orally (p.o) and served as normal control.

Group 2: injected (i.p.) only with $0.2 \mathrm{mg} / \mathrm{kg}$ b.w. of the snake venom and served as venom control.

Group 3 and 4: injected (i.p.) with $0.2 \mathrm{mg} / \mathrm{kg}$ b.w. of the snake venom, then after 30 min., they were administered orally (p.o) with 100 $\mathrm{mg} / \mathrm{kg} \mathrm{b.w}$. of the $n$-hexane and ethylacetate fractions of the extract respectively.

Group 5: injected (i.p.) with $0.2 \mathrm{mg} / \mathrm{kg}$ b.w. of the snake venom, then after $30 \mathrm{~min}$., they were administered (i.v.) with the standard conventional serum antivenin at the dose of 1 $\mathrm{ml} / 0.6 \mathrm{mg}$ venom.

All the groups received same volume of preparations and were monitored for 24 hours. Blood samples were then collected into plain tubes without anticoagulant. The coagulated blood samples were centrifuged at 3,000 rpm for $10 \mathrm{~min}$. to obtain the sera.

\section{Biochemical Analyses}

The following parameters were analyzed in the sera collected; Aspartate aminotransferase (AST) [21], Alanine aminotransferase (ALT) [21], Alkaline phosphatase (ALP) [22], $\gamma$-glutamyl transferase (GGT) [23], Lactate dehydrogenase (LH) [22], Total and Direct Bilirubin [24], Albumin [25] and Total protein [26].

\section{Data Analysis}

The data generated from the study are presented as mean \pm SEM and subjected to one way analysis of variance (ANOVA) and statistical difference between the means were separated using New Duncan's Multiple Range Test at $\mathrm{P}<0.05$ with the aid of a statistical package (IBM SPSS Statistics 20).

\section{RESULTS}

The results of the effect of $N$. nigricollis venom on the liver and its protection by the hexane and ethylacetate fractions are presented in Table 1. A significant $(\mathrm{P}<0.05)$ increase in the activities of serum aspartate transaminase (AST) and lactate dehydrogenase (LDH) as well as significant increase in the levels of total and direct bilirubin were observed 24 $\mathrm{h}$ after administration of $0.2 \mathrm{mg} / \mathrm{kg}$ b.w. of venom in the venom control rats compared to the normal control group. On the other hand, a significant decrease $(\mathrm{P}<0.05)$ in the serum levels of albumin (ALB) and total proteins (TP) were observed in envenomed albino rats. Among the two (2) fractions administered to the envenomed rats, only hexane fraction was able to significantly $(\mathrm{P}<0.05)$ reduce the activity of the serum LDH compared to the venom control group. None of the fractions or the standard antivenin reduced the serum AST, but the levels of total and direct bilirubin were significantly $(\mathrm{P}<0.05)$ lowered in the envenomed rat compared to the venom control group. In contrast, the standard antivenin (but none of the administered fractions) significantly increased the serum TP. The serum levels of ALT, ALP and GGT were not significantly $(\mathrm{P}>0.05)$ altered by the administration of $0.2 \mathrm{mg} / \mathrm{kg}$ b.w. of venom when compared to the normal control group. 
Table-1: Liver Function Indices of Envenomed Rats Treated with Hexane and Ethylacetate Leaf Fractions of $A$. indica

\begin{tabular}{|c|c|c|c|c|c|}
\hline \multirow{2}{*}{$\begin{array}{l}\text { Test } \\
\text { Parameters }\end{array}$} & \multicolumn{5}{|l|}{ Treatment } \\
\hline & Normal Control & Venom Control & $\begin{array}{l}\text { Venom + Hexane } \\
\text { Fraction }\end{array}$ & $\begin{array}{l}\text { Venom + Ethylacetate } \\
\text { Fraction }\end{array}$ & $\begin{array}{l}\text { Venom + Standard } \\
\text { Antivenin }\end{array}$ \\
\hline AST (U/l) & $36.00 \pm 3.66^{\mathrm{a}}$ & $149.67 \pm 4.90^{b}$ & $139.50 \pm 6.36^{b}$ & $158.33 \pm 18.93^{b}$ & $159.00 \pm 9.90^{b}$ \\
\hline ALT (U/l) & $27.00 \pm 2.83^{\mathrm{a}}$ & $45.00 \pm 3.45^{\mathrm{a}}$ & $27.00 \pm 1.66^{\mathrm{a}}$ & $38.00 \pm 2.55^{\mathrm{a}}$ & $37.50 \pm 6.36^{\mathrm{a}}$ \\
\hline ALP (U/l) & $277.50 \pm 29.71^{\mathrm{a}}$ & $281.67 \pm 15.23^{\mathrm{a}}$ & $235.00 \pm 19.50^{\mathrm{a}}$ & $205.33 \pm 5.51^{\mathrm{a}}$ & $229.50 \pm 12.03^{\mathrm{a}}$ \\
\hline GGT (U/l) & $9.00 \pm 1.41^{\mathrm{a}}$ & $17.33 \pm 1.15^{\mathrm{a}}$ & $13.00 \pm 1.28^{\mathrm{a}}$ & $11.67 \pm 11.36^{\mathrm{a}}$ & $16.50 \pm 2.12^{\mathrm{a}}$ \\
\hline LDH (U/l) & $200.50 \pm 16.57^{\mathrm{a}}$ & $851.33 \pm 114.93^{\mathrm{c}}$ & $493.00 \pm 13.84^{b}$ & $708.33 \pm 10.64^{\mathrm{c}}$ & $672.50 \pm 74.06^{\mathrm{c}}$ \\
\hline TB (mg/dl) & $0.78 \pm 0.04^{\mathrm{a}}$ & $2.90 \pm 0.15^{b}$ & $0.86 \pm 0.79^{\mathrm{a}}$ & $1.10 \pm 0.81^{\mathrm{a}}$ & $1.00 \pm 0.41^{\mathrm{a}}$ \\
\hline $\mathrm{DB}(\mathrm{mg} / \mathrm{dl})$ & $0.20 \pm 0.02^{\mathrm{a}}$ & $0.61 \pm 0.02^{b}$ & $0.25 \pm 0.06^{\mathrm{a}}$ & $0.27 \pm 0.13^{\mathrm{a}}$ & $0.23 \pm 0.07^{\mathrm{a}}$ \\
\hline ALB (g/l) & $37.50 \pm 2.12^{b}$ & $28.67 \pm 1.15^{\mathrm{a}}$ & $30.00 \pm 2.83^{\mathrm{a}}$ & $30.00 \pm 2.00^{\mathrm{a}}$ & $32.50 \pm 0.71^{\mathrm{a}}$ \\
\hline $\mathrm{TP}(\mathrm{g} / \mathrm{l})$ & $78.50 \pm 0.71^{b}$ & $60.33 \pm 2.50^{\mathrm{a}}$ & $62.50 \pm 4.94^{\mathrm{a}}$ & $61.33 \pm 4.93^{\mathrm{a}}$ & $68.00 \pm 1.66^{\mathrm{ab}}$ \\
\hline
\end{tabular}

Results in Table 1 are presented as Mean \pm SEM $(n=6)$. Values carrying different superscripts from the normal control for each parameter are significantly $(\mathrm{P}<0.05)$ different using ANOVA and Duncan multiple range test. AST $=$ Aspartate Transaminase, ALT $=$ Alanine Transaminase, ALP = Alkaline phosphatase, GGT $=\gamma$-Glutamyl Transferase, $\mathrm{LDH}=$ Lactate Dehydrogenase, $\mathrm{TB}=$ Total Bilirubin, $\mathrm{DB}=$ Direct Bilirubin, $\mathrm{ALB}=$ Albumin, $\mathrm{TP}=$ Total Protein.

\section{DISCUSSION}

In this study, the significant increase in the serum AST and LDH levels in the rats envenomed with the $N$. nigricollis venom agreed with the work reported by Mohammed et al., [27] that the Naja haje venom induced a significant increase in liver AST activity which may be due to destruction of hepatic cellular organelles and intracellular liberation of these enzymes. However, report from Mirakabadi et al., [28] revealed elevated activities of ALT, ALP and AST due to envenomation with cobra venom.

Liver injury is among the common and most serious symptoms of cobra snake envenomation [2931]. AST and ALT together with GGT and LDH enzymes are markers for hepatocellular damage and ALT enzyme is essentially present in hepatocytes [32]. Animals injected with $N$. nigricollis venom showed an increase in AST and ALT activities as reported by James et al., [33] due to the cytotoxins present in the venom $[4,34]$.

The levels of serum albumin and total proteins in this study showed significant decreases in the venom control rats compared to the normal control group (Table 1). Similarly, envenomed rats administered with the hexane and ethylacetate fractions presented significant decrease in the levels of the albumin and the total proteins. This implies that, these fractions were not capable of maintaining the levels of these proteins as obtained in the normal control group. This result agreed with the research reported by Al-Sadoon et al., [35] that there was a reduction in the level of total proteins in envenomed rats and proposed that, the observed effects on the parameters might suggest that the snake venom could have disturbed protein synthesis in hepatocytes due to cellular damage leading to protein loss. James et $a l .$, [33] discovered that the injection of crude venom of $N$. nigricollis caused reduction in serum total proteins and albumin, which is in agreement with the present study as both albumin and total protein serum levels were significantly decreased.

Snake venom cytotoxins are highly basic amphipathic proteins and they constitute as much as 40$70 \%$ of cobra venom [4]. They include lytic factors, cobramins, cytolysins and membranotoxins [36]. However, inactivation of these cytotoxic proteins can neutralize the lethality of the cobra venom.

\section{CONCLUSION}

The advantages of herbal remedies are that, they are cheap, readily available, stable at room temperature and could neutralize a wide range of venom toxins. The fractionated extracts of the A. indica leaf showed a remarkable protection on the hepatic tissue against the $N$. nigricollis venom with varying degrees of efficacy. Therefore, this research has provided a scientific proof on the antivenom properties of A. indica leaf, and the plant extracts can be used for detoxification of the snake venom toxicity.

\section{REFERENCES}

1. Sani, I., Umar, R. A., Hassan, S. W., \& Faruq, U. Z. (2018). Antisnake venoms and their mechanisms of action: A review. Saudi J. Med. Pharm. Sci, 4(5), 512-520.

2. Haruna, A. K., \& Choudhury, M. K. (1995). In vivo antisnake venom activity of a furanoid diterpene from Aristolochia albida Duch (Aristolochiaceae). Indian Journal of Pharmaceutical Sciences, 57(5), 222-224.

3. Sani, I., Umar, R. A., Hassan, S. W., Faruq, U. Z., Bello, F., \& Abdulhamid, A. (2019). Protective Effect of Azadirachta indica Leaf Fractionated Extracts on Renal and Haematological Indices 
against Snake Venom Toxicity in Albino Rats. Res J Med Plants, 13(3):103-108.

4. Sani, I., Umar, R. A., Hassan, S. W., Faruq, U. Z., Abdulhamid, A., Bello, F., \& Fakai, I. M. (2019). Major Enzymes from Snake Venoms: Mechanisms of Action and Pharmacological Applications. Asian Journal Biol Sci, 12(3):396-403.

5. Hossain, J., Biswas, A., Rahman, F., Mashreky, S. R., Dalal, K., \& Rahman, A. (2016). Snakebite Epidemiology in Bangladesh: A national community based health and injury survey. Health, 8, 479-486.

6. El-Mahmood, A. M., Ogbonna, O. B., \& Raji, M. (2013). The antibacterial activity of Azadarichta indica (neem) seeds extracts against bacterial pathogens associated with eye and ear infections. Journal of medicinal plants research, 4(14), 1414-1421.

7. Biswas, K., Chattopadhyay, I., Banerjee, R. K., \& Bandyopadhyay, U. (2002). Biological activities and medicinal properties of neem (Azadirachta indica). Current Science-Bangalore, 82(11), 13361345.

8. Ali, A. (1999). Textbook of Pharmacognosy. New Delhi, India: Publication and Information Directorate.

9. Kokate, C., Purohit, A. P., \& Gokhale, S. B. (2010). Pharmacognosy. Maharashtra, India: Nirali Prakashan.

10. Sani, I., Hassan, S. W., Faruq, U. Z., \& Bello, F. (2020). Isolation of Antisnake Venom Agents from Azadirachta Indica (A. Juss) Leaf Extracts. Academic Journal Chemistry, 5(2), 1016.

11. Koul, A., Mohan, V., \& Bharati, S. (2014). Azadirachta indica mitigates DMBA-induced hepatotoxicity: a biochemical and radiometric study. Indian J Biochem Biophys, 51:37-45.

12. Sunarwidhi, A. L., Sudarsono, S., \& Nugroho, A. E. (2014). Hypoglycemic effect of combination of Azadirachta indica A. Juss. and Gynura procumbens (Lour.) Merr. ethanolic extracts standardized by rutin and quercetin in alloxaninduced hyperglycemic rats. Advanced pharmaceutical bulletin, 4(Suppl 2), 613-618.

13. Baligar, N. S., Aladakatti, R. H., Ahmed, M., \& Hiremath, M. B. (2014). Hepatoprotective activity of the neem-based constituent azadirachtin-A in carbon tetrachloride intoxicated Wistar rats. Canadian journal of physiology and pharmacology, 92(4), 267-277.

14. Bhanwra, S., Singh, J., \& Khosla, P. (2000). Effect of Azadirachta indica (Neem) leaf aqueous extract on paracetamol-induced liver damage in rats. Indian journal of physiology and pharmacology, 44(1), 64-68.

15. Kale, B. P., Kothekar, M. A., Tayade, H. P., Jaju, J. B., \& Mateenuddin, M. (2003). Effect of aqueous extract of Azadirachta indica leaves on hepatotoxicity induced by antitubercular drugs in rats. Indian Journal of Pharmacology, 35(3), 177180 .

16. Aboubakar, O. B. F., Bella, N. M. T., Ngo, L. T. E., Bilanda, D. C., \& Dimo, T. (2012). Antihypertensive activity of Jateorhiza macrantha (Menispermaceae) aqueous extract on ethanolinduced hypertension in wistar. Int $J$ Pharm Pharm Sci, 4(2), 293-298.

17. AUCC. (2009). Guide to the use and care of experimental animals. Animal use and Care Committee, National Veterinary Research Institute, Vom, Nigeria: 1.

18. Goswami, P. K., Samant, M. A. Y. U. R. I., \& Srivastava, R. S. (2014). Snake venom, anti-snake venom \& potential of snake venom. International Journal of Pharmacy and Pharmaceutical Sciences, 6(5), 4-7.

19. Razi, M. T., Asad, M. H. H. B., Khan, T., Chaudhary, M. Z., Ansari, M. T., Arshad, M. A., \& Najam-us-Saqib, Q. (2011). Antihaemorrhagic (Antivenom) potentials of Fagonia cretica against Pakistani Cobra venom (Naja naja karachiensis). Nat. Prod. Res, 25(20), 1902-1907.

20. Dupont, S., Caffin, N., Bhandari, B., \& Dykes, G. A. (2006). In vitro antibacterial activity of Australian native herb extracts against foodrelated bacteria. Food Control, 17(11), 929-932.

21. Reitman, S., \& Frankel, S. (1957). A colorimetric method for the determination of serum glutamic oxalacetic and glutamic pyruvic transaminases. American journal of clinical pathology, 28(1), 56-63.

22. Rec, G. S. (1972). Optimised standard colourimetric methods: Determination of alkaline phosphatase. Journal Clin Chem Clin Biochem, 10:182-185.

23. Tietz, N. W. (1995). Clinical Guide to Laboratory Test. 2nd Ed., W. B. Saunders Co., Philadelphia, USA, 286.

24. Koch, T. R., \& Doumas, B. T. (1982). Bilirubin: Total and conjugated, modified Jendrassik-Grof method. Am Ass Clin Chem, 113.

25. Spencer, K., \& Price, C. P. (1971). Determination of serum albumin using Bromoscresol techniques. Annals Clin Biochem, 14:105-115.

26. Doumas, B. T. (1975). Standards for total serum protein assays - a collaborative study. Clinical chemistry, 21(8), 1159-1166.

27. Mohamed, A. H., El-Serougi, M. S., \& Hanna, M. M. (1969). Observations on the effects of Echis carinatus venom on blood clotting. Toxicon, 6(3), 215-219.

28. Assafim, M., Ferreira, M. S., Frattani, F. S., Guimarães, J. A., Monteiro, R. Q., \& Zingali, R. B. (2006). Counteracting effect of glycyrrhizin on the hemostatic abnormalities induced by Bothrops jararaca snake venom. British journal of pharmacology, 148(6), 807-813.

29. Al-Jammaz, I. (1995). Effects of the venom of Walterinnesia aegyptia and Echis coloratus on 
solute levels in the plasma of albino rats. J. King. Saud Univ, 7, 63-69.

30. Rahmy, T. R., \& Hemmaid, K. Z. (2000). Histological and histochemical alterations in the liver following intramuscular injection with a sublethal dose of the Egyptian cobra venom. Journal of natural toxins, 9(1), 21-32.

31. Adzu, B., Abubakar, M. S., Izebe, K. S., Akumka, D. D., \& Gamaniel, K. S. (2005). Effect of Annona senegalensis rootbark extracts on Naja nigricotlis nigricotlis venom in rats. Journal of ethnopharmacology, 96(3), 507-513.

32. Abdel Moneim, A. E., Othman, M. S., Mohmoud, S. M., \& El-Deib, K. M. (2013). Pomegranate peel attenuates aluminum-induced hepatorenal toxicity. Toxicology mechanisms and methods, 23(8), 624-633.
33. James, O., Godwin, E. U., \& Otini, I. G. (2013). In vivo neutralization of Naja nigricollis venom by Uvaria chamae. American Journal of Biochemistry \& Biotechnology, 9(3), 224-234.

34. Dufton, M. J., \& Hider, R. C. (1988). Structure and Pharmacology of Elapid Cytotoxins. Pharmacol Ther, 36:1-40.

35. Al-Sadoon, M. K., Abdel Moneim, A. E., Diab, M. M., \& Bauomy, A. A. (2013). Hepatic and renal tissue damages induced by Cerastes cerastes gasperetti crude venom. Life Sci. J, 10(4), 191197.

36. Gasanov, S. E., Dagda, R. K., \& Rael, E. D. (2014). Snake venom cytotoxins, phospholipase $\mathrm{A} 2 \mathrm{~s}$, and $\mathrm{Zn2+-dependent} \mathrm{metalloproteinases:}$ mechanisms of action and pharmacological relevance. Journal of clinical toxicology, 4(1), 1000181. 